\title{
Cardiopulmonary response to oxygen therapy in hypoxaemic chronic airflow obstruction
}

\author{
J M HUNT, J COPLAND, C F McDONALD, C E BARTER, P D ROCHFORD, \\ R J PIERCE \\ From the Department of Thoracic Medicine, Repatriation General Hospital, Heidelberg, Victoria, Australia
}

ABSTRACT The acute change in pulmonary artery pressure in response to oxygen may have prognostic value for patients with chronic obstructive pulmonary disease treated with long term domiciliary oxygen. A study was carried out to elucidate the mechanism of the acute cardiorespiratory response to oxygen in such patients and to determine whether it can be quantified non- 5 invasively. The effects of acute oxygen administration (100\% for 20 minutes and $28 \%$ oxygen for $24 \vec{z}$ hours) were assessed by non-invasive means and right heart catheterisation in 17 patients with severe stable hypoxaemic chronic obstructive pulmonary disease. Measurements included change in the $\frac{\Phi}{3}$ ratio of dead space to tidal volume (VD/VT), effective pulmonary capillary blood flow (by rebreathing $\underset{\mathbb{\Phi}}{\widetilde{D}}$ and single breath soluble gas uptake: QRB, QSB), left ventricular ejection fraction (radionuclide ventriculography), and $M$ mode echocardiographic estimates of ventricular diameters and fractional $\mathscr{\infty}$ shortening. These values were compared with those obtained from right heart catheter measurements of pulmonary artery pressure, cardiac index (thermodilution and direct carbon dioxide Fick: QTD, QFICK), and pulmonary vascular resistance. Oxygen administration resulted in a significant fall in pulmonary artery pressure, QTD, and QRB and a significant increase in VD/VT. The fall in QRB after $100 \%$ oxygen breathing for 20 minutes correlated strongly with the fall in pulmonary artery pressure $\frac{\circ}{D}$ $(\mathrm{r}=0 \cdot 86)$. There was no correlation between the fall in pulmonary artery pressure and the fall in QsB or the rise in $\mathrm{VD} / \mathrm{VT}$. Left ventricular ejection fraction did not change significantly. Echocardiography was technically unsatisfactory because of lung hyperinflation. Apart from a possible relation between $\dot{\mathrm{V}}_{2} \mathrm{max}$ and fall in pulmonary artery pressure after 24 hours of $28 \%$ oxygen breathing $(\mathrm{r}=0.49$, $\mathrm{p}<0 \cdot 1)$ none of the baseline respiratory function measurements predicted the fall in pulmonary artery pressure or QRB. It is concluded that the cardiopulmonary response to acute oxygen breathing in patients with hypoxic chronic obstructive pulmonary disease includes a reduction in pulmonary artery pressure and cardiac output and a redistribution of pulmonary blood flow, and that rebreathing measurements of effective pulmonary blood flow can be used to quantify this response non-invasively.

\section{Introduction}

The presence of cor pulmonale in patients with chronic obstructive pulmonary disease is associated with a poorer prognosis. ${ }^{12}$ Cor pulmonale is related to pulmonary hypertension, which is probably sympathetically mediated ${ }^{3}$ and is at least initially largely reversible. In the chronic state structural changes in the pulmonary arterial tree also contribute.

Address for reprint requests: Dr R J Pierce, Respiratory Function Unit, Repatriation General Hospital, Heidelberg West, Victoria 3081, Australia.

Accepted 28 June 1989
Relief of hypoxaemia by administration of sup- $\rightarrow$ plemental oxygen on a domiciliary basis has been shown to have a beneficial effect on survival in two N large multicentre trials ${ }^{45}$ in patients with chronic obstructive pulmonary disease and cor pulmonale. 0 Relief of hypoxic pulmonary hypertension has long $\mathrm{\omega}$ been held to be the cause of the improved survival, though recent studies have suggested improvement ince end organ oxygen delivery as an alternative or ad- $\overline{\mathbb{D}}$ ditional mechanism. ${ }^{6}$ No strong prognostic indicators $\stackrel{\oplus}{+}$ emerged from the early domiciliary oxygen studies 70 that could identify the patients who are more likely to $\stackrel{\vec{\Phi}}{\Phi}$ have a survival advantage with oxygen therapy. $\stackrel{\mathbb{\Omega}}{\stackrel{\circ}{\circ}}$ Identification of these patients is important as it would $\stackrel{\mathbb{Q}}{\varrho}$ 
spare the expense, inconvenience, and potential hazards of long term domiciliary oxygen treatment for patients unlikely to benefit.

Ashutosh et $a l^{8}$ recently reported that a fall in pulmonary artery pressure ( $\triangle \mathrm{PAP}$ ) of over $5 \mathrm{~mm} \mathrm{Hg}$ in response to 20 hours of $28 \%$ oxygen was a good predictor of improved survival at two and three years in patients with severe airways disease and cor pulmonale. The presence of pulmonary hypertension and lack of pulmonary vasodilator response to oxygen breathing have also been reported by Keller et al ${ }^{9}$ to be associated with a worse prognosis in chronic obstructive lung disease. The main predictive test in both of these studies, however, requires right heart catheterisation and is thus of limited general applicability for the large population of patients requiring assessment for domiciliary oxygen treatment.

The aims of the present study were to investigate the mechanisms of acute changes in the pulmonary and systemic circulation in response to administration of oxygen to patients with hypoxic chronic obstructive pulmonary disease and to examine the capacity of various non-invasive measurements to detect these changes. The non-invasive measurements were the soluble gas uptake estimation of effective pulmonary blood flow, dead space:tidal volume ratio, gated blood pool ventriculographic estimates of left ventricular ejection fraction and $\mathbf{M}$ mode echocardiographic estimates of ventricular contractility and size. Soluble gas uptake estimates of effective pulmonary blood flow using rebreathing (QRB) and single breath (QSB) methods are now well established in normal subjects $^{1013}$ and have been applied more recently to chronic airflow obstruction ${ }^{1415}$ and restrictive lung disease. ${ }^{16}$ Measurements of effective pulmonary blood flow may be affected by change in the distribution of pulmonary blood flow as well as by change in cardiac output. Discrepancies between the responses to oxygen in these measurements may shed light on the mechanisms underlying the response to oxygen. Oxygen treatment may cause an increase in dead space:tidal volume ratio $(\mathrm{VD} / \mathrm{VT})^{17}$ and in left ventricular ejection fraction in some patients with chronic obstructive lung disease. ${ }^{7}$

\section{Methods}

We studied consecutive patients with severe chronic obstructive lung disease referred to the thoracic unit of Heidelberg Repatriation Hospital for assessment for long term oxygen treatment during 18 months, starting in April 1985. Patients fulfilled the following criteria:

$1 \mathrm{FEV}_{1}<50 \%$ predicted $^{18}$ and $\mathrm{FEV}_{1} / \mathrm{FVC}<70 \%$.

2 Arterial oxygen tension $\left(\mathrm{PaO}_{2}\right)$ either (i) $<55$

$\wedge \mathrm{mm} \mathrm{Hg}(7.3 \mathrm{kPa})$ or (ii) $<60 \mathrm{~mm} \mathrm{Hg}(8.0 \mathrm{kPa})$ in the presence of clinical features of right heart failure (oedema, raised central venous pressure or right ventricular gallop) at the time of study or in the past.

3 Absence of left ventricular disease as assessed by history, physical examination, chest radiography and electrocardiography.

4 Persistence of criteria 1-3 after a period of three weeks' intensive bronchodilator treatment to ensure clinical stability.

Approval for the study was obtained from the hospital ethics committee. Patients were admitted to hospital after giving written informed consent. Baseline respiratory function measurements included flow-volume curves (Hewlett Packard 9871A and heated Fleish pneumotachograph) before and after $200 \mu \mathrm{g}$ salbutamol by metered dose inhaler, carbon monoxide uptake measurement by the single breath method with a 10 second breath hold time (transfer test-PK Morgan Ltd), and resting arterial blood gas analysis (Radiometer ABL 2). A progressive cycle exercise test was performed with $50 \mathrm{kpm}$ increments of work rate each minute until a symptom limited maximum workload had been achieved; maximum oxygen uptake $\left(\dot{\mathrm{V}}_{2 \max }\right)$ was calculated.

A technetium- $99 \mathrm{~m}$ gated blood pool scan was performed and left ventricular ejection fraction calculated, a large field of view gamma camera with computer (Informatek) analysis being used.

Each patient then underwent insertion of a Swan Ganz flow directed right heart catheter (Edwards laboratory $93 \mathrm{~A} 131 \mathrm{H} 7 \mathrm{~F}$ ) into the pulmonary artery through an antecubital vein. A catheter was also inserted into the radial artery. With the patient seated and breathing room air via a two way valve and mouthpiece and following a period of quiet rest, a series of measurements were made, including duplicate measurements of systemic arterial and pulmonary arterial blood gas tensions. Pulmonary artery pressure was measured in triplicate, systolic and diastolic pressures being averaged over at least three respiratory cycles. Mean pulmonary artery pressure was taken from the mean electrical signal, the accuracy of which had been verified by planimetered averages of pressure tracings.

Triplicate thermodilution estimates of cardiac output were made with an Edward's Laboratories cardiac output computer (9520A) and $10 \mathrm{ml}$ boluses of ice cold saline. Pulmonary vascular resistance (PVR) was calculated. Resting direct Fick cardiac output estimates were made from simultaneous measurements of carbon dioxide production (mixed expired gas) and arterial and mixed venous carbon dioxide contents. A comparison of oxygen and carbon dioxide Fick estimates was made for room air measurements. Duplicate measurements of VD/VT ratio were made 
from minute ventilation (pneumotachograph) and mixed expired and arterial carbon dioxide tension $\left(\mathrm{PCO}_{2}\right)$.

$$
\mathrm{VD} / \mathrm{VT}=\frac{\mathrm{PaCO}_{2}-\mathrm{PECO}_{2}}{\mathrm{PaCO}_{2}}-\frac{\text { VD valve }}{\mathrm{VT}}
$$

These were followed by duplicate resting estimates of pulmonary blood flow made by both rebreathing (QRB) and single breath (Q́SB) techniques ${ }^{14}$ with a gas mixture containing argon and difluoromonochloromethane (Freon 22) and a respiratory mass spectrometer (Centronics MGA200) for gas analysis. The order of measurements within the series was randomised for each patient. We allowed a minimum three minute washout after each soluble gas uptake measurement.

After the measurements with the patient breathing room air had been obtained the patients were switched via the two way valve (without their knowledge) to breathing $100 \%$ oxygen from a Douglas bag. Twenty minutes later measurements of pulmonary artery pressure, thermodilution and Fick cardiac output, VD/VT, QRB and QSB were repeated. The gas mixture, containing argon $8 \%$, Freon $3 \%$, and oxygen $40 \%$ with the balance nitrogen, was used for both room air and oxygen breathing measurements of QRB and QsB.

Low flow oxygen was then administered to the patient, who was kept at rest continuously, for 24 hours via a Ventimask at a concentration of $28 \%$, or greater (up to $35 \%$ ) if required to achieve a $\mathrm{PaO}_{2}$ of over $60 \mathrm{~mm} \mathrm{Hg}$. All pressure measurements, $\mathrm{VD} / \mathrm{VT}$, and $Q$ measurements were again repeated and the catheters were then removed. After a further 24 hours of breathing low flow oxygen, the radionuclide measurements of LVEF were repeated.

\section{ANALYSIS}

All measurements of cardiac output were expressed and analysed in terms of the cardiac index (cardiac output/body surface area). Comparisons were made between the catheter derived measurements of pulmonary artery pressure, pulmonary vascular resistance, and Fick and thermodilution cardiac output and the measurements derived from the non-invasive tests after both $100 \%$ oxygen ( 20 minutes) and $28 \%$ oxygen (24 and 48 hours) by means of Student's $t$ test and Wilcoxon rank sign test. Absolute measurements and change in response to oxygen breathing were compared. Correlations were performed by the method of least squares and Kendall's ranking method. $\chi^{2}$ analysis using $2 \times 2$ contingency tables with Yates's continuity correction was used to compare responses between methods of measurement.

\section{Results}

Sixteen male patients and one female fulfilling the
Table 1 Baseline functional characteristics (mean (SD) values) of the 17 study patients

\begin{tabular}{|c|c|}
\hline $\begin{array}{l}\text { Age } \\
\mathrm{PaO}_{2} \\
\mathrm{PaCO}_{2} \\
\mathrm{FEV}_{1} \\
\mathrm{FEV}_{1} / \mathrm{FVC} \\
\text { TLCO } \\
\mathrm{KCO} \\
\dot{\mathrm{VO}}_{2} \max \end{array}$ & 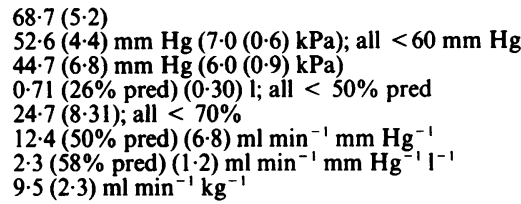 \\
\hline
\end{tabular}

For abbreviations see under "Methods."

selection criteria were entered into the study. Their mean age and baseline functional characteristics are given in table 1 and mean values for the catheter $\overrightarrow{0}$ measurements (PAP, PVR, QTD, and QFICK), the $\mathscr{O}^{\circ}$ soluble gas uptake measurements (QRB and QSB), and 0 $\mathrm{VD} / \mathrm{VT}$, minute ventilation and tidal volume? measurements at the three measurement times- $z$ baseline, after 20 minutes breathing $100 \%$ oxygen and after 24 hours breathing $28 \%$ oxygen-in table $2 . \stackrel{\oplus}{3}$ Because of poor reproducibility of QSB in these patients with very severe airflow obstruction, adequate results were obtained in only eight of the first $\overrightarrow{0}$ 10 subjects studied so the test was discontinued.

\section{EFFECT OF OXYGEN BREATHING}

Mean pulmonary artery pressure fell significantly after both $100 \%$ and $28 \%$ oxygen treatment. The fall in pulmonary artery pressure after $100 \%$ oxygen $\stackrel{\circ}{\perp}$ administration was over $5 \mathrm{~mm} \mathrm{Hg}$ in five patients and over $4 \mathrm{~mm} \mathrm{Hg}$ in nine. There was a decrease in mean $\mathrm{O}$ PVR but this just failed to be significant $(p<0 \cdot 1)$. The fall in thermodilution cardiac output was significant only after 20 minutes of $100 \%$ oxygen breathing; the fall in the direct Fick measurements of cardiac output was not significant. The rebreathing soluble gas uptake measurement of pulmonary blood flow fell ${ }_{0}^{\times}$ significantly after both $100 \%$ and $28 \%$ oxygen.

Table 2 Mean (SD) changes in right heart catheter and non-invasive measurements in response to oxygen $\left(\mathrm{O}_{2}\right)$ therapy in 17 subjects except where specified otherwise

\begin{tabular}{|c|c|c|c|}
\hline & Air & $\begin{array}{l}100 \% \mathrm{O}_{2} \\
\text { for } 20 \mathrm{~min}\end{array}$ & $\begin{array}{l}28 \% \mathrm{O}_{2} \\
\text { for } 24 \text { hours }\end{array}$ \\
\hline $\begin{array}{l}\text { PAP (mm Hg) } \\
\left.\text { PVR (dyne. s. cm }{ }^{5}\right) \\
\text { QTD }\left(1 / \mathrm{min} / \mathrm{m}^{2}\right) \\
\oint_{\text {FICK }\left(1 / \mathrm{min} / \mathrm{m}^{2}\right)} \\
\text { ORB }\left(1 / \mathrm{min} / \mathrm{m}^{2}\right) \\
\text { QSB }\left(1 / \mathrm{min} / \mathrm{m}^{2}\right) \ddagger \\
\text { VD } / \mathrm{VT} \\
\text { VE }(1 / \mathrm{min}) \\
\text { VT }(1)\end{array}$ & $\begin{array}{c}28.0(8 \cdot 1) \\
415(179) \\
2.78(0.54) \\
2.25(0.78) \\
1.75(0.55) \\
1.44(0.39) \\
0.61(0.08) \\
12.50(3.84) \\
0.63(0.19)\end{array}$ & $\begin{array}{c}24.1(7.5)^{*} \\
389(170) \dagger \\
2.43(0.46)^{*} \\
2.15(0.73) \\
1.48(0.35)^{*} \\
1.18(0.60) \\
0.64(0.06)^{*} \\
11.96(2.77) \\
0.61(0.19)\end{array}$ & $\begin{array}{c}24.9(7.6)^{*} \\
376(184) \\
2.61(0.68) \\
2.14(0.53) \\
1.46(0.44)^{*} \\
1.64(0.70) \\
0.60(0.06) \\
11.75(1.89) \\
0.67(0.26)\end{array}$ \\
\hline
\end{tabular}

*Significant change from air measurements $(\mathrm{p}<0.05)$.

$+0.1>\mathrm{p}>0.05$.

tEight subjects.

For abbreviations see under "Methods." 
QRB gave significantly lower results than QTD for both baseline and post-oxygen measurements (all $\mathrm{p}<0.001$ ). Both levels of oxygen breathing produced a greater percentage fall in QRB $(15.4 \%$ for $100 \%$ oxygen, $16.6 \%$ for $28 \%$ oxygen) than in QTD $(12.6 \%$, $6 \cdot 1 \%)$ or QFICK $(4 \cdot 4 \%, 4.9 \%)$ but the differences were not significant for either the percentage or the absolute fall. Mean VD/VT increased $(p<0.05)$ after the breathing of $100 \%$ oxygen and $\mathrm{VD} / \mathrm{VT}$ rose by more than 0.05 in five patients. There were no significant changes in minute ventilation $(\dot{\mathrm{V}} \mathrm{E}), \mathrm{VT}$, or frequency of breathing after either $100 \%$ or $28 \%$ oxygen administration.

\section{RELATION BETWEEN FALL IN PULMONARY ARTERY} PRESSURE AND OTHER VARIABLES

There was a strong correlation between the fall in pulmonary artery pressure and the fall in $Q_{R B}$ $(r=0.86, p<0.0001)$ in response to the acute administration of $100 \%$ oxygen for 20 minutes (figure and table 3). The fall in pulmonary artery pressure was also significantly related to the fall in QTD for both $100 \%$ and $28 \%$ oxygen but not to the fall in QSB or the increase in VD/VT after oxygen (table 3).

None of the baseline characteristics was related to change in pulmonary artery pressure $(\triangle \mathrm{PAP})$ or $\Delta \mathrm{VD} / \mathrm{VT}$ except for $\dot{\mathrm{V}}_{2}$ during cycle exercise and $\triangle$ PAP, which was of borderline statistical significance $(\mathrm{r}=0.47, \mathrm{p}<0.1)$.

FICK CARDIAC OUTPUT, ECHOCARDIOGRAPHY AND LEFT VENTRICULAR EJECTION FRACTION Comparison of Fick cardiac output measurements based on carbon dioxide production with those based on oxygen uptake were available for the resting studies during breathing of room air in 15 patients. Mean (SD) carbon dioxide based estimates of $5.43(2.72)$ $\mathrm{l} / \mathrm{min}$ and oxygen based estimates of $5.36(2.32) \mathrm{l} / \mathrm{min}$ did not differ significantly.

M mode echocardiographic estimates of ventricular size and contractility proved technically difficult in most patients because of hyperinflated lung fields overlying the right heart and no useful results were obtained.

Left ventricular ejection fraction did not change in response to 48 hours of low flow oxygen administration. The test was therefore discontinued after the first

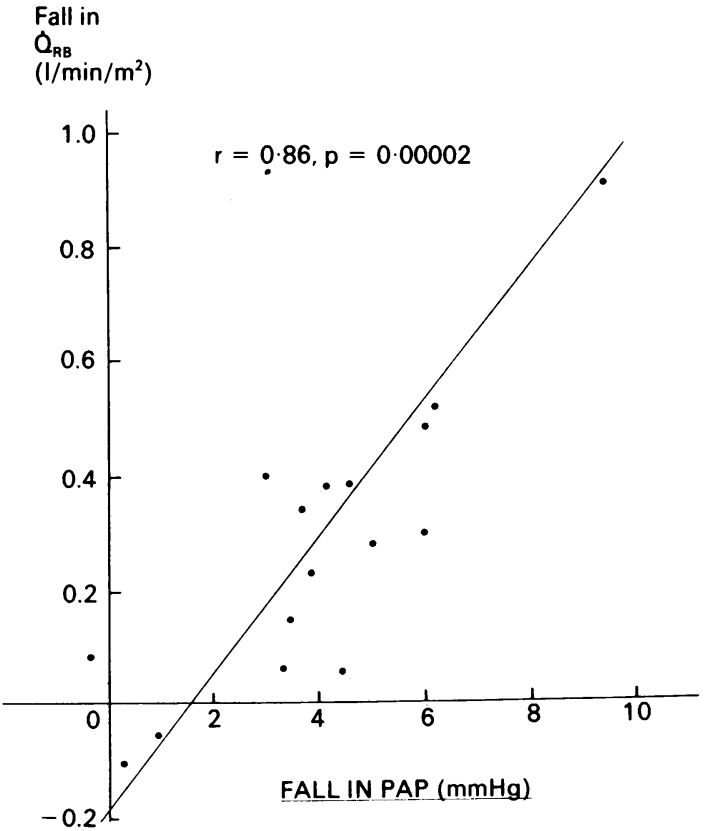

Relation between change in the rebreathing soluble gas uptake estimate of pulmonary blood flow $\left(\triangle \dot{Q}_{R B}\right)$ and change in mean pulmonary artery pressure $(\triangle P A P)$ in response to breathing $100 \%$ oxygen for 20 minutes. The linear correlation coefficient is given.

nine patients; mean (SD) baseline left ventricular ejection fraction was $58.6(6 \cdot 0)$ before and $59.4(5 \cdot 1)$ $1 /$ min after 48 hours of $28 \%$ oxygen.

REPEATABILITY OF $\dot{Q}_{R B}, Q_{s B}$, AND Vd/vt The reproducibility of the non-invasive measurements was assesssed from duplicate estimates as the coefficient of variation (SD/mean). This was $17 \cdot 3 \%$ for QRB, 31\% for QSB, and 3.0\% for VD/VT.

\section{Discussion}

A fall in cardiac output and effective pulmonary blood flow coincided with a fall in pulmonary artery pressure on administration of oxygen in this study. Of the various measurements assessed, the rebreathing soluble gas uptake measurement of the effective blood

Table 3 Correlation between the fall in pulmonary artery pressure and other indices (values given are linear correlation coefficients)

\begin{tabular}{llllll}
\hline & $\Delta P V R\left(\right.$ dyne. s. $\left.\mathrm{cm}^{5}\right)$ & $\Delta \dot{Q}_{T D}\left(l / \mathrm{min} / \mathrm{m}^{2}\right)$ & $\Delta \dot{Q}_{R B}\left(l / \mathrm{min} / \mathrm{m}^{2}\right)$ & $\Delta V D / V T$ & $\dot{V} o_{2} \max (\mathrm{ml} / \mathrm{min} / \mathrm{kg})$ \\
\hline $20 \mathrm{~min}$ of $100 \% \mathrm{O}_{2}$ & 0.01 (NS) & $0.49(\mathrm{p}<0.05)$ & $0.86(\mathrm{p}<0.0001)$ & -0.38 (NS) & 0.40 (NS) \\
$24 \mathrm{~h} \mathrm{of} 28 \% \mathrm{O}_{2}$ & -0.26 (NS) & $0.67(\mathrm{p}<0.01)$ & $0.31(\mathrm{NS})$ & -0.30 (NS) & 0.47 (NS)* \\
\hline
\end{tabular}

$* 0.05<\mathrm{p}<0.01$.

For abbreviations see under "Methods." 
flow (QRB) gave the best correlation with the currently proposed standard for oxygen responsiveness-a fall in pulmonary artery pressure. QRB fell with both $28 \%$ and $100 \%$ oxygen administration.

High concentration oxygen administration has been shown to lower cardiac output, pulmonary artery pressure, and pulmonary vascular resistance, ${ }^{19-21}$ whereas low flow oxygen administration has caused variable effects on cardiac output, some studies showing an increase, ${ }^{72}$ some no change, ${ }^{523}$ and some a decrease. ${ }^{2425}$

Thermodilution cardiac output measurements decreased after acute $100 \%$ oxygen administration for 20 minutes whereas the fall in QFICK was smaller and not significant. There are various postulated mechanisms for a fall in cardiac output. There may be relief of sympathetically mediated hypoxic systemic venoconstriction (especially peripheral venules) causing an increase in venous capacitance and a decrease in venous return. Alternatively, relief of reflex cardiac stimulation due to tissue hypoxia and via carotid and aortic chemoreceptor stimulation ${ }^{13}$ may occur. These mechanisms are distinct from the mechanism frequently held responsible for the fall in pulmonary artery pressure - namely, relief of hypoxic pulmonary arteriolar vasoconstriction, which may perhaps also be sympathetically mediated ${ }^{3}$ and which of itself might be expected to result in an increase rather than a decrease in cardiac output. Wilson and Dempsey ${ }^{19}$ suggested that the fall in pulmonary artery pressure is in part due to a fall in cardiac output and in part due to a decrease in pulmonary vascular resistance.

Differences between true cardiac output and effective pulmonary blood flow have not been reported previously in this context. Any redistribution of pulmonary blood flow away from well ventilated areas as a result of decreased hypoxic reflex vasoconstriction in poorly ventilated areas should produce a greater fall in $Q_{\mathbf{R B}}$ than that resulting from a decrease in true cardiac output (QTD or QFICK). QRB did fall by more than QTD and QFICK in our subjects, though the difference was not significant-possibly because of the large variation in response. This, in conjunction with the increase in $\mathrm{VD}_{\mathrm{D}} / \mathrm{VT}_{\mathrm{T}}$, suggests that in some patients at least there may have been a redistribution of pulmonary blood flow in addition to a fall in cardiac output.

Increased survival with long term domiciliary oxygen treatment may be due to improved tissue and end organ oxygen delivery ${ }^{6}$ rather than relief of right heart strain and cor pulmonale. QRB is influenced both by changes in oxygen delivery (reflex changes in cardiac output) and by pulmonary blood flow distribution (relief of pulmonary vasoconstriction) and might therefore be expected to predict long term survival associated with domiciliary oxygen. Being non-invasive and easily repeatable it may be useful for following therapeutic responses over a period of time. $\overrightarrow{\vec{S}}$ The coefficient of variation of $Q$ RB measurements in our patients with severe airflow obstruction (mean $\underline{ }$ FEV, $26 \%$ predicted) was $17 \cdot 3 \%$. This is higher than the values of $10.2 \%$ and $10.5 \%$ based on triplicate $\underset{\Omega}{2}$ estimates for patients with less severe airflow obstruction (mean $\mathrm{FEV}_{1} 64 \%$ and $42 \%$ predicted respec- $\infty$ tively) obtained previously in our laboratory, ${ }^{14}$ and $\vec{O}$ compares with a value of $8.7 \%$ for normal subjects. $\overrightarrow{\vec{\omega}}$ The poorer repeatability of QRB measurements in $\hat{\sigma}^{\circ}$ patients with more severe airflow obstruction places constraints on the use of QRB as a detector of oxygen responsiveness in these subjects. Estimates suggest $\stackrel{f}{+}$ that for triplicate measurements a change of the order $\overrightarrow{-}$ of $25 \%$ would be required for $95 \%$ confidence that a real fall had occurred. Obtaining the needed multiple 0 replicates in these circumstances when relatively small 음 real changes in cardiac output are expected is time $\rightarrow$ consuming, as three to five minutes are required for $z$ washout of foreign gases during each test. The measurements are not demanding for the patients, $\stackrel{\frac{1}{3}}{3}$ however, and multiple measurements are feasible. QSB measurements, being much less reproducible in severe $\overrightarrow{\vec{\theta}}$ airflow obstruction (coefficient of variation $31 \%$ ), are of little value in these circumstances.

Administration of $100 \%$ oxygen increased VD/VT in our patients in the absence of any significant change in minute ventilation or tidal volume, providing furthero evidence of a redistribution of pulmonary blood flow. ֶ An increase in VD/VT in response to oxygen and $\stackrel{\mathbb{Q}}{\complement}$ aminophylline has been well described by Read and $\overrightarrow{\vec{O}}$ coworkers, ${ }^{17227}$ who introduced the concept of vas- 3 cular responders (increase in VD/VT with oxygen) and non-responders (no change in $V_{D} / V_{T}$ with oxygen) among patients with chronic obstructive lung disease. This response to oxygen is thought to be due to응 increased blood flow to low $\dot{\mathrm{V}} / \mathbf{Q}$ areas, resulting in $\mathrm{a}_{\times}$ net worsening in $\dot{V} / Q$ balance. In a large series of 0 patients with chronic obstructive lung disease who were not receiving oxygen Lindsay and $\operatorname{Read}^{28}$ showed a poorer overall survival in vascular responders than in non-responders for a given degree of airflowo obstruction. The ratio of responder to non-responder $\square$ VD/VT status in normal and chronic obstructive lungo disease populations was $2: 1$ in these studies and may be genetically determined. Rebuck and Vandenberg ${ }^{29} \mathrm{O}$ found in 10 patients that $\mathrm{VD} / \mathrm{VT}$ responder status was $N_{0}$ not related to absolute levels of pulmonary artery స్ట pressure or pulmonary vascular resistance but that it correlated with the fall in pulmonary artery pressure during oxygen breathing. All these findings are com- $-\frac{\tau}{\varnothing}$ patible with the hypothesis that pulmonary vascularos responsiveness carries an adverse prognosis in chronic obstructive lung disease because of its tendency to worsen cor pulmonale in patients not treated with $\vec{\odot}$ oxygen; it should carry a favourable prognosis for 
patients treated with domiciliary oxygen because of their greater capacity to obtain relief of pulmonary hypertension.

In contrast to Rebuck and Vandenberg, we did not find a correlation between the increase in $\mathrm{VD} / \mathrm{VT}$ and the fall in pulmonary artery pressure after oxygen administration. This may have been because our patients had more severe airflow obstruction than those of Rebuck and Vandenberg, higher values for $\mathrm{VD} / \mathrm{VT}$ and pulmonary artery pressure, less responsiveness, and lower values of $\mathrm{PaO}_{2}$. They may therefore have had more fixed vascular damage and less reversible (hypoxic) pulmonary vasoconstriction. VD/VT increased by more than 0.05 after oxygen in only seven of our 17 patients, in contrast to the two thirds found in Read's original large series and the seven out of 10 patients in the studies of Rebuck and Vandenberg. The fall in pulmonary artery pressure in our patients may have had a larger contribution from systemic circulatory effects (increased venous capacitance causing decreased venous return or decreased cardiac stimulation or both) and less pulmonary vasodilatation.

We compared the use of carbon dioxide for Fick estimates of cardiac output with those using oxygen. The use of carbon dioxide rather than oxygen produces less accurate measurements generally because of the greater solubility of carbon dioxide and the smaller arteriovenous carbon dioxide tension differences. Accurate measurements of oxygen uptake are impractical, however, during oxygen administration. There was good agreement between the carbon dioxide and the oxygen methods for resting cardiac output in our subjects, suggesting that carbon dioxide based estimates are acceptable in these circumstances.

Like other workers, ${ }^{921}$ we failed to detect any significant change in left ventricular ejection fraction during oxygen administration. Right ventricular ejection fraction has been shown not to change in response to oxygen. ${ }^{617}$

A maximum oxygen uptake of more than $6.5 \mathrm{ml} /$ $\mathrm{min} / \mathrm{kg}$ during symptom limited cycle exercise has been shown to predict both the acute response of pulmonary artery pressure to $28 \%$ oxygen for 24 hours and long term survival with domiciliary oxygen treatment in patients with chronic obstructive lung disease. $^{8}$ In our patients the correlation between $\dot{\mathrm{VO}}_{2}$ max and $\triangle$ PAP after 24 hours of $28 \%$ oxygen approached statistical significance $(p<0 \cdot 1)$, whereas no other index of baseline respiratory function showed any relation to $\triangle \mathrm{PAP}$ or $\Delta \mathrm{VD} / \mathrm{VT}$.

In this study oxygen administration caused a fall in cardiac output, a redistribution of pulmonary blood flow, and a fall in pulmonary artery pressure in patients with chronic obstructive lung disease and hypoxaemia. The pulmonary artery pressure response to acute oxygen administration correlated closely with the fall in QRB, a non-invasive measurement of cardiopulmonary function. Fall in pulmonary artery pressure is known to have predictive value for survival in patients with chronic obstructive lung disease receiving long term domiciliary oxygen therapy. Because of its non-invasive nature, $Q_{R B}$ is particularly suitable for repeated measurement in the same patient and may be useful for following cardiopulmonary responses to oxygen or other therapeutic interventions over a period of time. Follow up of these and larger series of patients is required to confirm whether acute changes in $\mathrm{QRB}, \mathrm{VD} / \mathrm{VT}$, or any other non-invasive marker of cardiopulmonary responsiveness to oxygen administration are of practical value in predicting which patients with chronic obstructive lung disease are most likely to benefit from long term oxygen therapy.

We thank Drs L B Arkles, G Gill, and Mr Peter Osborne (department of nuclear medicine) for the performance of all radionuclide scans in this study. The research was supported by the Department of Veterans' Affairs, Australia.

\section{References}

1 Mitchell RS, Webb NC, Filey GF. Chronic obstructive bronchopulmonary disease III factors affecting prognosis. Am Rev Respir Dis 1964;89:878-96.

2 Traver GA, Cline MG, Burrows B. Prediction of mortality in chronic obstructive pulmonary disease. $\mathrm{Am}$ Rev Respir Dis 1979;119:895-902.

3 Haneda T, Nakujiran T, Shirato K, et al. Effects of oxygen breathing on pulmonary vascular input impedance in patients with pulmonary hypertension. Chest 1983;3:520-7.

4 Report of the Medical Research Council Working Party. Long term domiciliary oxygen therapy in chronic hypoxic cor pulmonale complicating chronic bronchitis and emphysema. Lancet 1981;i:681-6.

5 Nocturnal Oxygen Therapy Trial Group. Continuous or nocturnal oxygen therapy in hypoxaemic chronic obstructive lung disease- a clincial trial. Ann Intern Med 1980;93:391-8.

6 Morrison DA, Henry R, Goodman H. Preliminary study of the effects of low flow oxygen on oxygen delivery and right ventricular function in chronic lung disease. Am Rev Respir Dis 1986;133:390-5.

7 Ashutosh K, Mead G, Dunsky M. Early effects of oxygen administration and prognosis in chronic obstructive pulmonary disease and cor pulmonale. Am Rev Respir Dis 1983;127:399-401.

8 Ashutosh K, Dunsky M. Non-invasive tests for responsiveness of pulmonary hypertension to oxygenprediction of survival in patients with chronic obstructive lung disease and cor pulmonale. Chest 1987; 92:393-9.

9 Keller R, Ragaz A, Borer P. Predictors of early mortality in patients with long-term oxygen therapy. Respiration 1985;48:216-21. 
10 Teichman J, Adaro F, Veicsteinas A, Cerretelli P, Piiper J. Determination of pulmonary blood flow by rebreathing of soluble gases. Respiration 1974;31: 296-309.

11 Sackner MA, Greeneltoch D, Herman MS, et al. Diffusing capacity, membrane diffusing capacity, capillary blood volume, pulmonary tissue volume and cardiac output recorded by a rebreathing technique. Am Rev Respir Dis 1975;13:157-65.

12 Denison DM, Davies NJH, Brown DJ. A theoretical comparison of single breath and rebreathing methods of studying soluble gas exchange in the lungs. In: Cumming G, Bonsignore GG, eds. Pulmonary circulation in health and disease New York: Plenum, 1980: 139-65.

13 Bush A, Busst CM, Johnson S, Denison DM. Rebreathing method for the simultaneous measurement of oxygen consumption and effective pulmonary blood flow during exercise. Thorax 1988;43:268-75.

14 Pierce RJ, McDonald CF, Thuys CA, Rochford PJ. Measurement of pulmonary blood flow by soluble gas uptake in chronic airflow obstruction. Thorax 1987; 42:605-14.

15 Pierce RJ, Payne CR, Williams SJ, Denison DM, Clark TJH. Comparison of intravenous and inhaled terbutaline in the treatment of asthma. Chest 1969;79: 506-11.

16 Bush A, Busst CM. Cardiovascular function at rest and on exercise in patients with cryptogenic fibrosing alveolitis. Thorax 1988;43:276-83.

17 Lee J, Read J. Effect of oxygen breathing on distribution of pulmonary blood flow in chronic obstructive lung disease. Am Rev Respir Dis 1967;96:1173-80.

18 Knudson RJ, Burrows B, Lebowitz MD. The maximal expiratory flow volume curve: its use in the detection of ventilatory flow abnormalities in a population study. Am Rev Respir Dis 1976;114:871.

19 Wilson RH, Hoseth W, Dempsey ME. The effects of breathing $99.6 \%$ oxygen on pulmonary vascular resistance and cardiac output in patients with pulmonary emphysema and chronic hypoxia. Ann Intern Med 1955;42:629-37.

20 Holt JH, Branscomb BV. Haemodynamic responses to controlled $100 \%$ oxygen breathing in emphysema. $J$ Appl Physiol 1965;20:215-20.

21 Tschopp JM, Gabathuler J, Righetti A, Junds AF. Comparative effects of acute oxygen breathing and terbutaline in patients with chronic obstructive pulmonary disease. A combined haemodynamics and radionuclide study. Eur J Respir Dis 1985;67:357-9.

22 Kitchin AH, Lowther CP, Matthews MB. The effects of exercise and of breathing oxygen enriched air in the pulmonary circulation in emphysema. Clin Sci 1961; 21:93-106.

23 Karetsky MS, Keighley JF, Mithoefer JC. The effects of oxygen administration on gas exchange and cardiopulmonary function in normal subjects. Respir Physiol 1971;12:361-70.

24 Degaute JP, Domemighetti R, Naeije R, Vincent JL, Treyaund D, Perrett CI. Oxygen delivery in acute exacerbation of chronic obstructive pulmonary disease. Am Rev Respir Dis 1961;124:26-30.

25 Lejuene P, Mols P, Naeije R, Hallemans R, Melot C. Acute haemodynamic effects of controlled oxygen therapy in decompensated chronic obstructive pulmonary disease. Crit Care Med 1984;12:1032-5.

26 Pain MCF, Charlton GC, Read J. Effect of aminophylline on distribution of pulmonary blood flow in obstructive lung disease. Am Rev Respir Dis 1967; 95:1005-14.

27 Read J, Lee J. Regional pulmonary vasoconstriction as an individual factor with genesis of cor pulmonale. Am Rev Respir Dis 1967;96:1181.

28 Lindsay DA, Read J. Pulmonary vascular responsiveness in the program of chronic obstructive lung disease. $\mathrm{Am}$ Rev Respir Dis 1972;105:242-50.

29 Rebuck AS, Vandenberg RA. The relationship between pulmonary arterial pressure and physiologic dead space in patients with obstructive lung disease. $A m$ Rev Respir Dis 1973;107:423-8. 